\section{Adult sequelae of child sexual abuse}

SIR: It was with great interest that we read the article about adult sequelae of child sexual abuse by Sheldrick (Journal, May 1991, 158(suppl. 10), 5562 ). We, too, have done research work on the prevalence and consequences of sexual abuse in childhood in psychiatric patients, and in a non-clinical sample. We feel that our findings (Kinzl \& Biebl, 1991) confirm and supplement Sheldrick's results.

The traumagenic dynamics of powerlessness and betrayal (Finkelhor \& Browne, 1985) were demonstrated in our patients. Together with a lack of emotional and social support on the part of the mother, the often-found ego weakness of the victim prevents an alloplastic mode of coping with the traumatic experience, which results in a labilisation, particularly in situations of separation and loss.

Compared with patients with mental disorders, the familial situation of the non-clinical sample with sexual abuse in childhood was significantly more frequently characterised by:

(a) more social support from extrafamilial confidant(e)s

(b) less frequent mental disorder on the part of the mother

(c) more positive experiences in partner relationships in later life

(d) less frequent and shorter-lasting incestuous sexual abuse by the father or stepfather.

Finkelhor, D. \& Browne, A. (1985) The traumatic impact of child sexual abuse: a conceptualization. American Journal of Orthopsychiatry, 55, 530-541.

KINZL, J. \& BiEBL, W. (1991) Sexual abuse of girls: aspects of the genesis of mental disorders and therapeutic implications. Acta Psychiatrica Scandinavica, 83, 427-431.

\author{
University Klinik für Psychiatrie \\ Innsbruck \\ Austria
}

JOHANN KINZL WILFRIED BIEBL

\section{Prognosis of depression in the elderly}

SIR: Meats et al (Journal, November 1991, 159, 659-663) make the interesting observation that in four studies using in-patient samples, a relatively good prognosis has been observed for depression in old age, whereas in studies including both outpatients and in-patients, outcome was less favourable. The authors suggest two possible explanations: either different thresholds for rating symptoms, or inter-district differences in therapeutic effectiveness.
It is possible that the means of selecting the samples has been responsible for the different findings reported to date. In addition, other possible hypotheses can be suggested to explain the differences in outcome between in-patient-only and mixed samples. Firstly, there may be a bias towards the admission of patients who, it is anticipated, will respond to in-patient treatment. Secondly, those patients in out-patient follow up are often cases of resistant depression. Those who have responded favourably to treatment have perhaps tended to be discharged.

Finally, and perhaps more worryingly, perhaps psychiatrists are spending too much energy keeping patients out of hospital, and perhaps we should be admitting a higher proportion of cases for intensive treatment. In other words, in-patient treatment may be a more effective therapeutic measure, and this improvement in prognosis, in turn, might be due to more intensive treatment or to careful planning at the time of discharge.

Consultant Psychiatrist

TOM DENING

Psychiatric Services for the Elderly

Fulbourn Hospital, Cambridge

\section{Decontextualisation and mythology}

SIR: Dr Littlewood is entitled to express his viewpoint on A History of Medicine in Papua New Guinea (Journal, August 1991, 159, 317) but his perjorative style is so littered with errors that the potential reader might well be more interested in the facts.

The book is described as "Whiggish" although there is nothing in the Shorter Oxford English Dictionary that would concur with such a deprecatory statement. There are no Whigs of any sort in Papua New Guinea.

He uses the American colloquialism 'medic', the word 'Melanesian' and the title 'Papua and New Guinea' all of which are grossly inappropriate. There are no 'medics' in Papua New Guinea; the word is unknown in the country. 'Melanesian' refers to a much wider geographical area than Papua New Guinea, and along with the use of 'Papua and New Guinea' shows an apparent lack of knowledge of the history, geography and name of the country.

He states that "a fuller account of how the different medical systems interact can be found in Frankel \& Lewis' A Continuing Trial of Treatment: Medical Pluralism in Papua New Guinea (1989)". This is incorrect. With all due respect to the authors of that volume, which has virtues in other respects and which is written by 12 non-medical ethnographers 